\title{
Platelet-rich plasma versus hyaluronic acid in the treatment of knee osteoarthritis: a meta-analysis
}

\author{
Jia Zhu Tang, Ming Jun Nie, Jian Zhong Zhao, Guang Cheng Zhang, Qing Zhang and Bo Wang*
}

\begin{abstract}
Background: This study aimed to evaluate the clinical efficacy of platelet-rich plasma (PRP) injection compared with hyaluronic acid (HA) injection for patients undergoing knee osteoarthritis.

Methods: We systematically searched electronic databases including PubMed, Embase, Web of Science, and the Cochrane Library on January 23, 2020 to identify relevant studies issued in English languages. The outcomes evaluating the efficacy of knee osteoarthritis (KOA) treatment were Western Ontario and McMaster Universities Arthritis Index (WOMAC) scores (WOMAC pain, function, stiffness, and total scores) at 1, 3, 6, and 12 months; International Knee Documentation Committee (IKDC) scores, Lequesne Index score, Visual Analog Scale (VAS) scores, EQ-VAS scores, and KOOS scores. The pooled data were analyzed by Stata 12.0.
\end{abstract}

Results: A total of 20 RCTs were enrolled in the present meta-analysis. The pooled results demonstrated that platelet-rich plasma (PRP) injection reduced pain more effectively than hyaluronic acid (HA) injection at 6-month and 12-month follow-up evaluated by WOMAC pain scores and VAS scores. EQ-VAS in the patients treated with PRP injection was lower than that in patients with HA injection at 12 months. Moreover, the patients with PRP injection had a better function recovery than those with HA injection at 1-month, 3-month, 6-month, and 12-month followup, as evaluated by WOMAC function scores. WOMAC total scores showed significant difference at 6-month and 12-month follow-up. The IKDC scores indicated PRP injection was significantly more effective than HA injection at 3 months and 6 months. However, the Lequesne Index scores, KOOS scores, and adverse events did not show any significant difference between groups.

Conclusion: Intra-articular PRP injection appeared to be more efficacious than HA injection for the treatment of KOA in terms of short-term functional recovery. Moreover, PRP injection was superior to HA injection in terms of long-term pain relief and function improvement. In addition, PRP injection did not increase the risk of adverse events compared to HA injection.

Keywords: Osteoarthritis, Platelet-rich plasma, Hyaluronic acid, Meta-analysis

\footnotetext{
* Correspondence: wangboortho@sina.com

Department of Joint Surgery, Affiliated Hospital of Jiangsu University,

Zhenjiang, Jiangsu Province, China
}

(C) The Author(s). 2020 Open Access This article is licensed under a Creative Commons Attribution 4.0 International License, which permits use, sharing, adaptation, distribution and reproduction in any medium or format, as long as you give appropriate credit to the original author(s) and the source, provide a link to the Creative Commons licence, and indicate if changes were made. The images or other third party material in this article are included in the article's Creative Commons licence, unless indicated otherwise in a credit line to the material. If material is not included in the article's Creative Commons licence and your intended use is not permitted by statutory regulation or exceeds the permitted use, you will need to obtain permission directly from the copyright holder. To view a copy of this licence, visit http://creativecommons.org/licenses/by/4.0/. The Creative Commons Public Domain Dedication waiver (http://creativecommons.org/publicdomain/zero/1.0/) applies to the data made available in this article, unless otherwise stated in a credit line to the data. 


\section{Background}

Knee osteoarthritis (KOA) is a common disease associated with progressive deterioration of the cartilage and narrowing of the joint space [1]. It was reported that KOA in the USA was nearly 27 million, and the number of KOA is continually growing due to the aging population [2, 3].

Patients often advance through multiple treatments to block the progresses; however, there are no therapies proven to alter the progression of KOA development [4]. Current treatments are mainly concentrated on the symptom's remission with the aim of pain relief and function recovery [5]. Nonsurgical therapies are met with both nonpharmacological and pharmacological approaches [6]. Diet and exercise are the two recommended nonpharmacological treatments but often with poor compliance [7]. Pharmacological treatments for KOA are focused on the administration of oral glucosamine, chondroitin, acetaminophen, celecoxib, glucosamine, and chondroitin [8]. However, the use of NSAIDs and analgesics is often accompanied with side effects [9].

Intra-articular injection, as a minimally invasive therapy, is reported safe and effective for the treatment of KOA [10]. Injections of intra-articular hyaluronic acid (HA) and platelet-rich plasma (PRP) are used as other non-surgical treatment options for the patients with KOA [11]. HA, a high-molecular weight glucosamine, is generated by chondrocytes, synoviocytes, and fibroblasts and responsible for the viscoelasticity and lubrication of the knee joint [12]. It is shown that HA concentrations in osteoarthritic knees have been reduced. Increasing evidences have demonstrated that $\mathrm{HA}$ is able to improve joint function, relieve pain, and reduce the dosage of analgesics [13].

Injection of intra-articular HA had been recommended in the management of patients with KOA by the American College of Rheumatology (ACR) in 2012 [14]. PRP is an autologous product derived from patients' own blood through the process of gradient density centrifugation. PRP contains various growth factors and other bioactive molecules, which may regulate the aberrant inflammatory processes, regenerate tissue structures and thus promote tissue healing [15]. Autologous PRP involves a minimum risk of immune reactions and transmission of infectious diseases, and it has been widely used for the recovery of rotator cuff tendinopathy [16]. Previously, a RCT conducted by Lin et al. [17] revealed that intraarticular injections of leukocyte-poor PRP can provide clinically significant functional improvement for at least 1 year in patients with mild-to-moderate osteoarthritis of the knee.

However, there is still no consensus about which treatment (i.e., PRP vs. HA) is the best possible treatment for knee OA. Di et al. [18] conducted a meta-analysis about
PRP versus $\mathrm{HA}$ for $\mathrm{KOA}$, and results found that PRP intra-articular injection may be an effective alternative treatment for KOA, though some included studies suggested that the efficacy of PRP was no better than HA. Nevertheless, some studies failed to show PRP providing a superior clinical improvement with respect to HA [19, 20]. This study aimed to compare the efficacy and safety of intra-articular PRP and HA for KOA patients.

\section{Methods}

This systematic review and meta-analysis are performed based on the guidance of the Preferred Reporting Items for Systematic Reviews and Meta-analysis (PRISMA) statement and Cochrane Handbook for Systematic Reviews of Interventions [21]. No ethical approval and patient consent are required because all analyses are based on previous published studies.

\section{Search strategy and literature selection}

We systematically searched electronic databases including PubMed, Embase, Web of Science and the Cochrane Library on January 23, 2020 to identify relevant studies issued in English languages. The search strategy was made for the use of Medical Subject Headings (MeSH) terms and correspondence keywords. The search strategies can be seen in Supplement S1. We also searched relevant reviews and meta-analyses to identify other eligible studies.

Two investigators (Jia Zhu Tang and Ming Jun Nie) independently conducted the initial searches and screened the titles and abstracts for selecting eligible studies. In addition, the reference lists from all the original articles and identified reviews were also manually scanned for additional relevant studies. If either reviewer observed a title or abstract meeting the eligibility criteria, full text of the study was retrieved.

\section{Inclusion and exclusion \\ Eligibility criteria}

The inclusion criteria were as follows:

1) Patients: patients diagnosed with KOA at any grading scale

2) Intervention: intra-articular injection with PRP for intervention

3) Comparison: intra-articular injection with HA for comparison

4) Outcomes: the outcomes concerning efficacy including Western Ontario and McMaster Universities Arthritis Index (WOMAC) scores (WOMAC pain, function, stiffness, and total scores) at 1, 3, 6 and 12 months; International Knee Documentation Committee (IKDC) scores, Lequesne Index scores, Visual Analog Scale (VAS) 
scores, EQ-VAS scores, Knee Injury and Osteoarthritis Outcome Scores (KOOS); the outcomes concerning safety including postoperative adverse events (pain, stiffness, dizziness, febrile syndrome, headache, flu, or infection). WOMAC scores were identified as the primary outcome due to the comprehensive reaction knee joint function.

5) Studies: only randomized controlled clinical trials were included

The exclusion criteria were as follows:

1) Patients who suffered from bilateral $\mathrm{KOA}$

2) Nonrandomized studies

3) Articles that which we were unable to obtain the relevant data for pooled analysis.

\section{Data extraction}

Two reviewers independently extracted data from each study using a standardized data extraction form. Disagreements were resolved by discussion, and those unresolved through discussion were reviewed by a third reviewer. The following variables were included: first author, publication year, country, number of participants, age, sex, body mass index, radiographic classification, and follow-up. Moreover, we collected injection doses, times, and intervals of PRP and HA injections. Primary outcomes included WOMAC pain and WOMAC function scores at 1, 3, 6, and 12 months. Secondary outcomes were WOMAC total scores, WOMAC stiffness scores, IKDC scores, VAS scores, EQ-VAS scores, KOOSs, Lequesne Index scores, and adverse events. We intended to contact authors for detail information when the reported data were inadequate.

\section{Risk of bias assessment}

Two reviewers (Jian Zhong Zhao and Guang Cheng Zhang) independently evaluated the risk of bias of each RCT by the Cochrane Risk of Bias tool. Each article was assessed based on the following seven items: random sequence generation (selection bias), allocation concealment (selection bias), blinding of participants and personnel (performance bias), blinding of outcome assessment (detection bias), incomplete outcome data

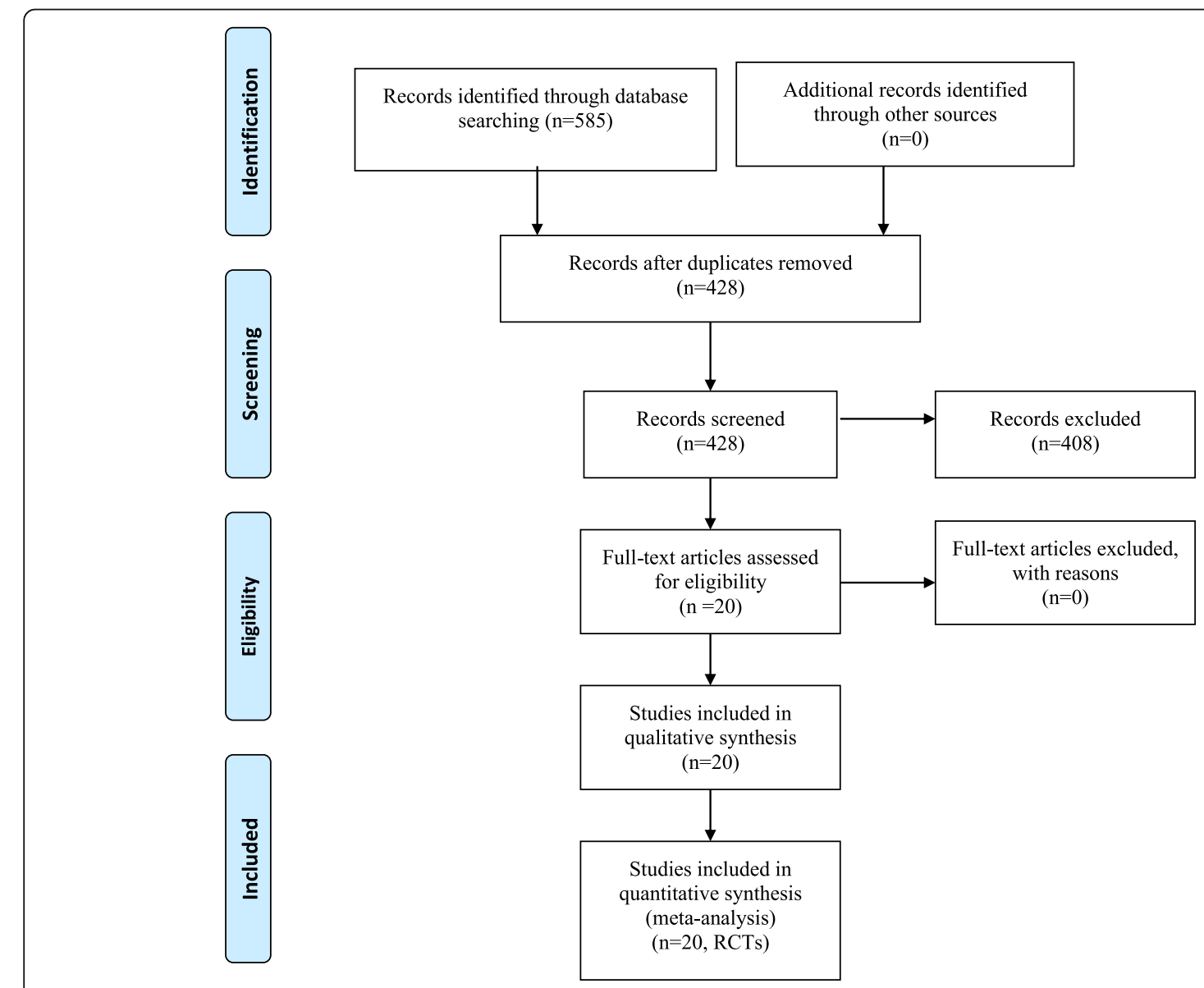

Fig. 1 Flowchart of the study search and inclusion criteria. 
(attrition bias), selective reporting (reporting bias), and other bias. Every item was scored as high, low, or unclear. Any discrepancies shall be settled by consensus between the two reviewers. If necessary, a third reviewer shall be consulted (Bo Wang).

\section{Statistical analysis}

As for outcomes measurements (WOMAC pain, function, and total scores; IKDC scores; and Lequesne scores) in each study, the mean difference between the baseline and post intervention was calculated to compare the efficacy of intervention with the control group. The present study was conducted by using Stata 12.0 (Stata Corp., College Station, TX, USA) for metaanalysis. The standard mean difference (SMD) and 95\% confidence interval (CI) were calculated for continuous outcomes (WOMAC pain, function, stiffness, and total scores; IKDC scores; VAS scores; EQ-VAS scores; KOOSs; and Lequesne scores), while risk ratios (RRs) with 95\% CIs were adopted for dichotomous outcome (adverse events). Heterogeneity among studies was accessed by using the $\mathrm{I}^{2}$ statistic. The $\mathrm{I}^{2}$ values of $25 \%$, $50 \%$, and $75 \%$ were respectively considered to be the cut-off points for low, moderate, and high heterogeneity. Random effects method was used for all meta-analyses. $P$ value $<0.05$ was considered to be of statistical significance.

\section{Results}

\section{Literature search}

Figure 1 shows the details of the literature search. A total of 190 records were identified as potentially relevant studies. By removing duplicates, scanning titles, and reading abstracts, 83 full-text articles were assessed for eligibility. Ultimately, 19 RCTs [17, 19, 20, 22-38] were included for data extraction and meta-analysis.

\section{Study characteristics}

The study characteristics are available in Table 1 . These studies were published from 2011 to 2019 with a total of 1281 patients. The sample size of the studies ranged from 10 to 104. There were 654 patients in the PRP injection group and 627 patients in the HA injection group. The follow-up period ranged from 3 to 18 months. The demographic features between the two groups in each study were similar. The administrated

Table 1 General characteristic of the included studies

\begin{tabular}{|c|c|c|c|c|c|c|c|c|c|c|c|}
\hline \multirow[t]{2}{*}{ Author } & \multirow[t]{2}{*}{ Country } & \multirow{2}{*}{$\begin{array}{l}\text { No. of } \\
\text { patients } \\
\text { (PRP vs } \\
\text { HA) }\end{array}$} & \multirow{2}{*}{$\begin{array}{l}\text { Age } \\
\text { (years, } \\
\text { PRP vs } \\
\text { HA) }\end{array}$} & \multirow{2}{*}{$\begin{array}{l}\text { Sex } \\
\text { (male, } \\
\text { PRP vs } \\
\text { HA) }\end{array}$} & \multirow{2}{*}{$\begin{array}{l}\text { BMI (PRP } \\
\text { vs HA) }\end{array}$} & \multicolumn{5}{|c|}{ Radiographic classification (PRP vs HA) } & \multirow{2}{*}{$\begin{array}{l}\text { Follow- } \\
\text { up (m) }\end{array}$} \\
\hline & & & & & & 0 & I & $\|$ & III & IV & \\
\hline Ahmad 2018 [22] & Egypt & $45 / 44$ & $56.2 / 56.8$ & $14 / 14$ & NS & $0 / 0$ & $8 / 7$ & $17 / 19$ & $20 / 18$ & $0 / 0$ & 6 \\
\hline Buendia-Lopez 2018 [23] & Spain & $33 / 32$ & $56.2 / 56.6$ & $16 / 15$ & 24.9/24.9 & $0 / 0$ & 18/18 & $15 / 14$ & $0 / 0$ & $0 / 0$ & 12 \\
\hline Cerza 2012 [24] & Italy & $60 / 60$ & $66.5 / 66.2$ & $25 / 28$ & NS & $0 / 0$ & $21 / 25$ & $24 / 22$ & $15 / 13$ & $0 / 0$ & 6 \\
\hline Cole 2017 [20] & USA & $49 / 50$ & $55.9 / 56.8$ & $28 / 20$ & $27.4 / 29$ & $0 / 0$ & $3 / 0$ & $26 / 27$ & $20 / 22$ & $0 / 0$ & 12 \\
\hline Di Martino 2019 [25] & Italy & $85 / 82$ & $52.7 / 57.5$ & $53 / 47$ & $27.2 / 26.8$ & NS & & & & & 60 \\
\hline Duymus 2017 [26] & Turkey & $33 / 34$ & $60.4 / 60.3$ & $1 / 1$ & $27.6 / 28.4$ & $0 / 0$ & $0 / 0$ & $22 / 24$ & $21 / 10$ & $11 / 0$ & 12 \\
\hline Filardo 2015 [19] & Italy & $94 / 89$ & $53.3 / 57.6$ & $60 / 52$ & $26.6 / 26.9$ & NS & NS & NS & NS & NS & 12 \\
\hline Gormeli 2017 [27] & Turkey & $39 / 39$ & $53.7 / 53.5$ & $16 / 17$ & 28.7/29.7 & $0 / 0$ & $26 / 30$ & & & $13 / 14$ & 6 \\
\hline Huang 2019 [28] & China & $40 / 40$ & $54.5 / 54.8$ & $25 / 19$ & $25.2 / 24.5$ & $0 / 0$ & $40 / 40$ & & $0 / 0$ & $0 / 0$ & 12 \\
\hline Li 2011 [29] & China & $15 / 15$ & $57.6 / 58.2$ & $6 / 7$ & $24.3 / 21.0$ & $0 / 0$ & $6 / 6$ & $2 / 3$ & $4 / 3$ & $3 / 3$ & 6 \\
\hline Lin 2019 [17] & China & $31 / 29$ & $61.2 / 62.5$ & $9 / 10$ & $24.0 / 26.3$ & $5 / 6^{\#}$ & $16 / 14^{\#}$ & 10/9\# & & & 12 \\
\hline Louis 2018 [30] & France & $24 / 24$ & $53.2 / 48.5$ & $14 / 11$ & $25.6 / 27.0$ & $0 / 0$ & $0 / 0$ & $24 / 24$ & & & 6 \\
\hline Montanez-Heredia 2016 [31] & Spain & $27 / 26$ & $66.3 / 61.5$ & $12 / 9$ & $29.0 / 30.4$ & $0 / 0$ & $5 / 2$ & $10 / 9$ & $12 / 15$ & $0 / 0$ & 6 \\
\hline Paterson 2016 [32] & Australia & $11 / 10$ & 49.9/52.7 & $8 / 7$ & 27.9/28.9 & $0 / 0$ & $0 / 0$ & $11 / 10$ & & $0 / 0$ & 3 \\
\hline Raeissadat 2015 [33] & Iran & $77 / 62$ & $56.9 / 61.1$ & $8 / 15$ & $28.2 / 27.0$ & $0 / 0$ & $5 / 0$ & $34 / 29$ & $29 / 23$ & $9 / 10$ & 12 \\
\hline Sanchez 2012 [34] & Spain & $89 / 87$ & $60.5 / 58.9$ & $43 / 42$ & 27.9/28.2 & $45 / 43^{\#}$ & $32 / 33^{\#}$ & $12 / 11^{\#}$ & & & 6 \\
\hline Su 2018 [35] & China & $25 / 30$ & $54.2 / 53.1$ & $11 / 12$ & $28.2 / 28.7$ & $0 / 0$ & $0 / 0$ & $16 / 13$ & $11 / 12$ & $0 / 0$ & 6 \\
\hline Vaquerizo 2013 [36] & Spain & $48 / 48$ & $62.4 / 64.8$ & $16 / 22$ & $30.7 / 31.0$ & NS & NS & & & & 12 \\
\hline Yu 2018 [37] & China & $104 / 88$ & $46.2 / 51.5$ & $50 / 48$ & NS & NS & NS & & & & 12 \\
\hline Tavassoli 2019 [38] & Iran & $28 / 27$ & $63.2 / 66.0$ & $5 / 8$ & $28.4 / 28.9$ & & $21 / 22$ & $35 / 32$ & & & 3 \\
\hline
\end{tabular}

NS not stated, PRP platelet-rich plasma, $H A$ hyaluronic acid

\# Ahlbäck grade, and the rest were $\mathrm{K}-\mathrm{L}$ grades 
Table 2 Detail treatment protocols of PRP and HA injections

\begin{tabular}{|c|c|c|c|c|c|c|c|}
\hline \multirow[t]{2}{*}{ Author } & \multicolumn{4}{|l|}{ PRP } & \multicolumn{3}{|l|}{$\mathrm{HA}$} \\
\hline & Injection dose (ml) & Times & Intervals & Type & Injection dose (ml) & Times & Intervals \\
\hline Ahmad 2018 [22] & 4 & 3 & 2 Weeks & LRP & $20 \mathrm{mg} / 2 \mathrm{ml} \mathrm{high}$ & 3 & 2 Weeks \\
\hline Buendia-Lopez 2018 [23] & 5 & NS & NS & LPP & $60 \mathrm{mg} / 2 \mathrm{ml}$ high & NS & NS \\
\hline Cerza 2012 [24] & 5.5 & 4 & Weekly & LPP & $20 \mathrm{mg} / 2 \mathrm{ml} \mathrm{high}$ & 4 & Weekly \\
\hline Cole 2017 [20] & 4 & 3 & Weekly & LPP & 16 mg/2 ml high (6 MDa) & 3 & Weekly \\
\hline Di Martino 2019 [25] & 5 & 3 & Weekly & LRP & 30 mg/2 ml high (> 1500 kDa) & 3 & Weekly \\
\hline Duymus 2017 [26] & 5 & 2 & Monthly & LRP & 40 mg/2 ml high (1600 kDa) & 1 & Monthly \\
\hline Filardo 2015 [19] & 5 & 3 & Weekly & LRP & 30 mg/2 ml high (> 1500 kDa) & 3 & Weekly \\
\hline Gormeli 2017 [27] & 5 & 3 & Weekly & LRP & $30 \mathrm{mg} / 2 \mathrm{ml}$ & 3 & Weekly \\
\hline Huang 2019 [28] & 2 & 3 & Weekly & LPP & 4 ml (500-730 kDa) & 3 & Weekly \\
\hline Li 2011 [29] & 3.5 & 3 & 3 Weeks & LRP & $2 \mathrm{ml}$ & 3 & 3 Weeks \\
\hline Lin 2019 & 5 & 3 & Weekly & LPP & $20 \mathrm{mg} / 2 \mathrm{ml}$ & 3 & Weekly \\
\hline Louis 2018 [30] & 3 & 1 & NS & LPP & $60 \mathrm{mg} / 3 \mathrm{ml}$ & 1 & NS \\
\hline Montanez-Heredia 2016 [31] & NS & 3 & 2 Weeks & LPP & NS & 3 & 2 Weeks \\
\hline Paterson 2016 [32] & 3 & 3 & Weekly & LRP & $3 \mathrm{ml}$ & 3 & Weekly \\
\hline Raeissadat 2015 [33] & 43,927 & 2 & Monthly & LRP & 20 mg/2 ml (500-730 kDa) & 3 & Weekly \\
\hline Sanchez 2012 [34] & 8 & 3 & Weekly & LPP & NS & 3 & Weekly \\
\hline Su 2018 [35] & 6 & 2 & 2 Weeks & LRP & $2 \mathrm{ml}$ & 5 & Weekly \\
\hline Vaquerizo 2013 [36] & 8 & 3 & 2 Weeks & LPP & NS & 1 & NS \\
\hline Yu 2018 [37] & $2-14$ & 4 & Weekly & LRP & $0.1-0.3 \mathrm{mg}$ & 4 & Weekly \\
\hline Tavassoli 2019 [38] & $4-6$ & 4 & 3 Weeks & LRP & 30 mg/2 ml (500-730 kDa) & 4 & Weekly \\
\hline
\end{tabular}

timing and dosage of PRP and HA injections are shown in Table 2, which were varied among these studies.

\section{Risk of bias}

Figures 2 and 3 reveal the risk of bias summary and graph of all included RCTs. Among the twenty RCTs, random sequence generation were recorded adequately in eighteen studies $[17,19,20,22,23,25-28,31-39]$ and unclear in two studies [24, 30]. Allocation concealment were recorded adequately in eleven studies $[17,19$, $20,23,27,28,32,34,36-38$ ], unclear in seven studies $[22,25,26,30,35,39]$, and high in two studies [24, 33]. The performance bias was recorded adequately in thirteen studies $[17,19,20,23,27,28,30-32,34,38]$, unclear in five study [26, 35-37, 39], and high in two studies [24, 33]. Only four studies [24, 27, 33, 35] reveal unclear risk of bias for other bias.

\section{Outcomes of the meta-analysis WOMAC total scores}

Figure 4 summarizes the WOMAC total scores comparing PRP injection with HA injection. A total of five [17, $24,26,35,38]$, eight $[17,24,26,28-30,35,38]$, nine [17, $23,24,26,28,29,34-36]$, and eight $[17,23,26,28,33$, 35-37] studies reported the WOMAC total scores at 1 ,
3,6 , and 12 months, respectively. The pooled data indicated that, compared with the HA group, PRP injection was associated with a decrease of the WOMAC total scores at 1 month $(\mathrm{SMD}=-0.84,95 \% \mathrm{CI}-1.48$ to $0.20, P=0.010), 6$ months $(\mathrm{SMD}=-1.14,95 \% \mathrm{CI}-1.88$ to $-0.40, P=0.002)$, and 12 months $(\mathrm{SMD}=-1.47,95 \%$ CI -2.23 to $-0.70, P=0.000)$. Nevertheless, there was no statistically significant difference between PRP and $\mathrm{HA}$ injections at 3 months $(\mathrm{SMD}=-0.13,95 \% \mathrm{CI}-0.78$ to $0.52, P=0.686)$. Heterogeneity was significant among these pooled results $\left(I^{2}=87.6 \%, 92.0 \%, 95.1 \%\right.$, and $95.3 \%$, respectively).

\section{WOMAC function scores}

The WOMAC function scores comparing PRP injection with $\mathrm{HA}$ injection are available in Fig. 5. A total of three $[26,35,38]$, four $[26,30,35,38]$, five $[23,26,34-36]$, and seven [23, 26, 31, 33, 35-37] studies described the function recovery evaluated by the WOMAC function scores at 1, 3, 6, and 12 months, respectively. The pooled results revealed PRP injection provided a better function recovery than $\mathrm{HA}$ injection at $3(\mathrm{SMD}=-1.18,95 \% \mathrm{CI}$ -2.03 to $-0.33, P=0.007), 6(\mathrm{SMD}=-1.44,95 \% \mathrm{CI}-$ 2.55 to $-0.34, P=0.011)$, and 12 months $(\mathrm{SMD}=-1.25$, $95 \% \mathrm{CI}-1.74$ to $-0.76, P=0.000)$. There was no 


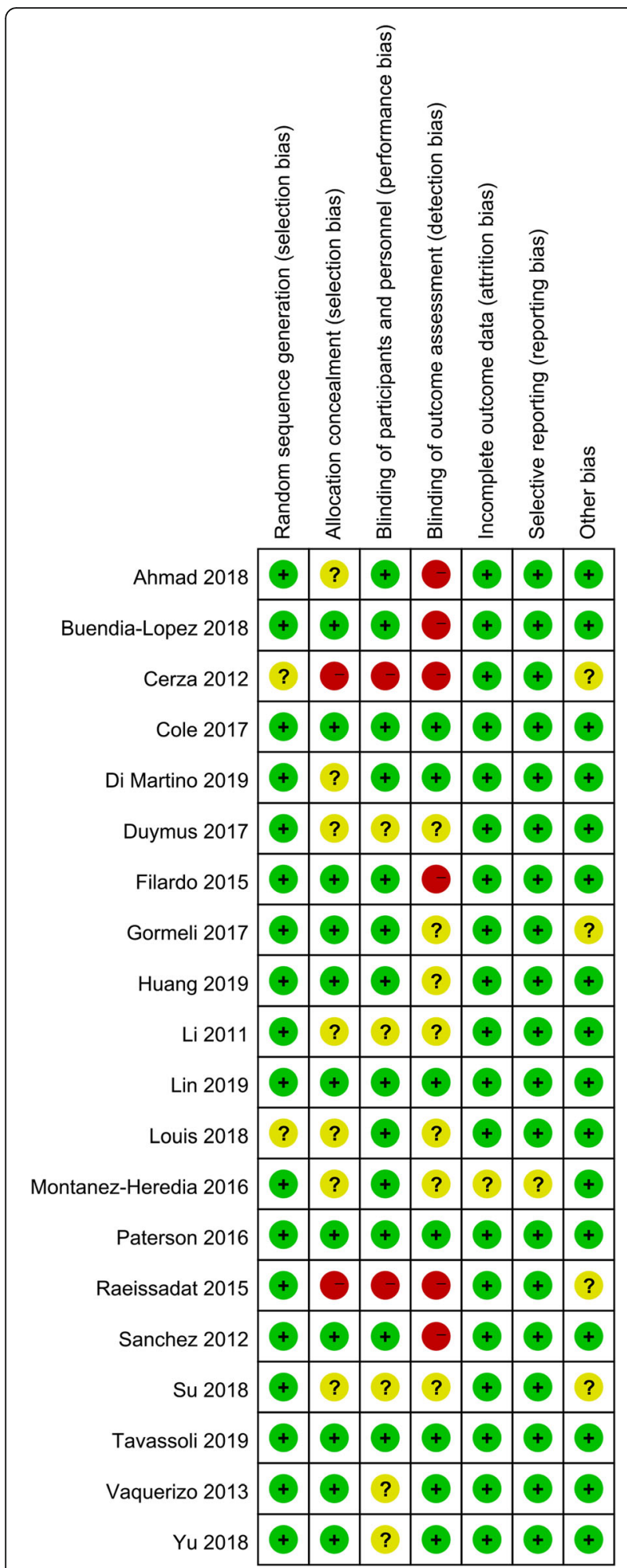

Fig. 2 Risk of bias summary of included in randomized controlled trials. 1, no bias; -, bias; ?, bias unknown statistically significant difference between PRP and HA injections for the WOMAC function scores at 1 month $(\mathrm{SMD}=-0.35,95 \% \mathrm{CI}-1.74$ to $1.04, P=0.622)$.

\section{WOMAC stiffness scores}

Figure 6 presents the WOMAC stiffness scores comparing PRP injection with HA injection. A total of three $[26,35,38]$, four $[26,30,35,38]$, three [26, 30, 35], and six $[26,35-37]$ studies showed the WOMAC stiffness scores at $1,3,6$, and 12 months, respectively. PRP injection showed more effective than HA injection in improving knee stiffness at $3(\mathrm{SMD}=-0.37,95 \% \mathrm{CI}-0.63$ to $-0.10, P=0.007$, Fig. 6), 6 (SMD $=-0.32,95 \%$ CI -0.62 to $-0.01 ; P=0.042$, Fig. 6) and 12 months (SMD $=-$ $0.73,95 \% \mathrm{CI}-0.90$ to $-0.57, P=0.000$, Fig. 6). However, the pooled results showed that there was no significant difference in knee stiffness improvement at 1 month $(\mathrm{SMD}=0.15,95 \% \mathrm{CI}-0.46$ to $0.76, P=0.624$, Fig. 6 ) between the PRP and HA injection groups.

\section{WOMAC pain scores}

The WOMAC pain scores comparing PRP injection with HA injection is shown in Fig. 7. A total of five [20, 26, $28,35,38]$, seven $[20,26,30,32,34,35,38]$, eight [20, $23,26,31,34-37]$, and eight [19, 20, 23, 26, 33, 35-37] studies investigated the WOMAC pain scores at $1,3,6$, and 12 months, respectively. The pooled results revealed patients with PRP injection got better improvement than those with $\mathrm{HA}$ injection at $6(\mathrm{SMD}=-1.29,95 \% \mathrm{CI}-$ 2.29 to $-0.29, P=0.012$, Fig. 7) and12 months (SMD = $0.91,95 \%$ CI -1.22 to $-0.60, P=0.000$, Fig. 7 ).

There was no significant difference between PRP and $\mathrm{HA}$ at 1 month $(\mathrm{SMD}=1.97,95 \% \mathrm{CI}-0.15$ to $4.08, P=$ 0.068, Fig. 7) and 3 months (SMD $=0.29,95 \% \mathrm{CI}-0.35$ to $0.94, P=0.376$, Fig. 7 ).

\section{VAS scores}

Figure 8 shows the VAS scores comparing PRP injection with HA injection. The patients with PRP injection had better pain relief than those with HA injection at 1 month (SMD $=0.42,95 \% \mathrm{CI}-0.45$ to $0.15, P<0.05$ ), 3 months $(\mathrm{SMD}=0.08,95 \% \mathrm{CI}-0.56$ to $0.67, P<0.05), 6$ months $(\mathrm{SMD}=-0.34,95 \% \mathrm{CI}-0.99$ to $0.45, P<0.05)$, and 12 months (SMD $=-0.72,95 \% \mathrm{CI}-1.06$ to $0.41, P<0.05)$.

\section{IKDC scores}

The IKDC scores comparing PRP injection with HA injection are available in Fig. 8. PRP injection was more effective than HA injection at 6 months (SMD $=8.65,95 \%$ CI 1.75 to $15.23, P<0.05$, Fig. 8). However, the pooled data suggested there was no significant discrepancy comparing PRP injection with HA injection at 2 months $(\mathrm{SMD}=-1.35,95 \% \mathrm{CI}-6.06$ to $3.35, P>0.05$, Fig. 8$)$ 


\section{Random sequence generation (selection bias)}

Allocation concealment (selection bias)

Blinding of participants and personnel (performance bias)

Blinding of outcome assessment (detection bias)

Incomplete outcome data (attrition bias)

Selective reporting (reporting bias)

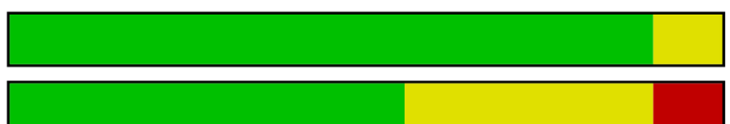

Other bias
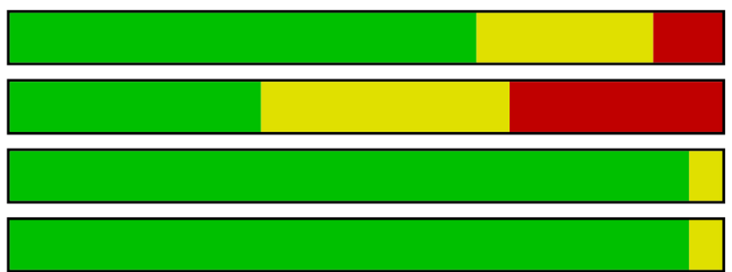

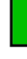

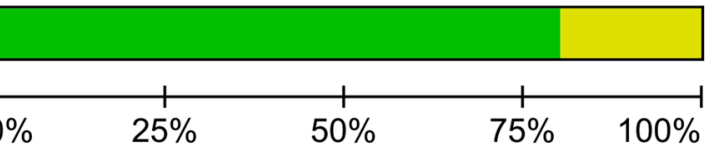

Low risk of bias

Unclear risk of bias

High risk of bias

Fig. 3 Risk of bias graph in randomized controlled trials

and 3 months $(\mathrm{SMD}=5.25,95 \% \mathrm{CI} 0.34$ to $8.95, P>$ 0.05, Fig. 8).

\section{Lequesne Index scores}

The Lequesne Index scores comparing PRP injection with $\mathrm{HA}$ injection are available in Fig. 7. PRP injection was more effective than HA injection for the Lequesne Index scores at 6 months $(\mathrm{SMD}=-0.72,95 \% \mathrm{CI}-1.95$ to $0.56, P<0.05$, Fig. 8 ).

\section{EQ-VAS scores}

The pooled data did not find any significant difference between PRP injection and HA injection at 2 months $(\mathrm{SMD}=0.68,95 \% \mathrm{CI}-2.10$ to $3.31, P>0.05$, Fig. 8$), 6$ months $(\mathrm{SMD}=4.35,95 \% \mathrm{CI}-2.31$ to $10.58, P>0.05$, Fig. 8 ) and 12 months (SMD $=3.12,95 \%$ CI 0.34 to 4.86 , $P>0.05$, Fig. 8).

\section{KOOSs}

The KOOSs comparing PRP injection with HA injection are presented in Fig. 8. The pooled analysis demonstrated that PRP was associated with a reduction of the symptom $(\mathrm{SMD}=-0.06,95 \% \mathrm{CI}-0.55$ to $0.59, P<0.05$, Fig. 8), pain (SMD $=-0.05,95 \% \mathrm{CI}-0.34$ to $0.26, P<$ 0.05 , Fig. 8), activities of daily life (SMD $=-0.16,95 \% \mathrm{CI}$ -0.43 to $0.34, P<0.05$, Fig. 8 ) and sport (SMD $=-0.06$, $95 \% \mathrm{CI}-0.31$ to $0.42, P<0.05$, Fig. 8 ).

\section{Adverse events}

Thirteen studies with a total of 1281 patients reported the incidence of advance events comparing PRP injection with HA injection advance events (Fig. 9). The pooled results demonstrated that there was no significant difference between PRP injection and HA injection $(\mathrm{RR}=1.00,95 \% \mathrm{CI} 0.80$ to $1.26, P=0.997)$, with no heterogeneity $\left(I^{2}=0 \%\right)$.

\section{Subgroup analyses}

Table 3 shows the results of subgroup analyses for the WOMAC total scores at 12 months. The subgroup analyses based on the number of PRP injections, PRP spinning approach (single or double), PRP classification (LP-PRP or LR-PRP), fresh or frozen PRP, whether an activator was used, and risk of bias (low or unclear/high) were conducted for exploring the WOMAC total scores at 12 months.

The findings of WOMAC pain, stiffness, function, and VAS at 12 months were consistent in all subgroup analyses except for the number of PRP injections, PRP single spinning approach, LP PRP, without using an activator, molecular weight, and structure subgroups. In the subgroups of $\geq 2$ injections, double spinning approach, LP-PRP, and activator use, we found that PRP was associated with significantly better WOMAC than $\mathrm{HA}$ at 12 months (Table 3).

In the subgroup analyses dividing into low and high molecular weight groups, results showed a PRP significant reduction in WOMAC at 12 months than $\mathrm{HA}$ with low molecular weight (SMD - 1.31, 95\% CI - 1.97 to 0.64], $P=0.000, I^{2}=92.2 \%$, Table 3 ), but not in HA with high molecular weight (SMD $-1.90,95 \% \mathrm{CI}=-4.53$ to $0.73, P=0.157, I^{2}=97.9 \%$, Table 3$)$. Moreover, there was a PRP significant reduction in WOMAC at 12 months than HA with no cross-link or unclear (SMD - 0.57, $95 \%$ CI -1.78 to $0.63, P=0.000, I^{2}=95.0 \%$, Table 3$)$, but not in HA with cross-link (SMD - 2.06, 95\% CI $=-3.20$ to $-0.92, P=0.352, I^{2}=96.2 \%$, Table 3 ). 


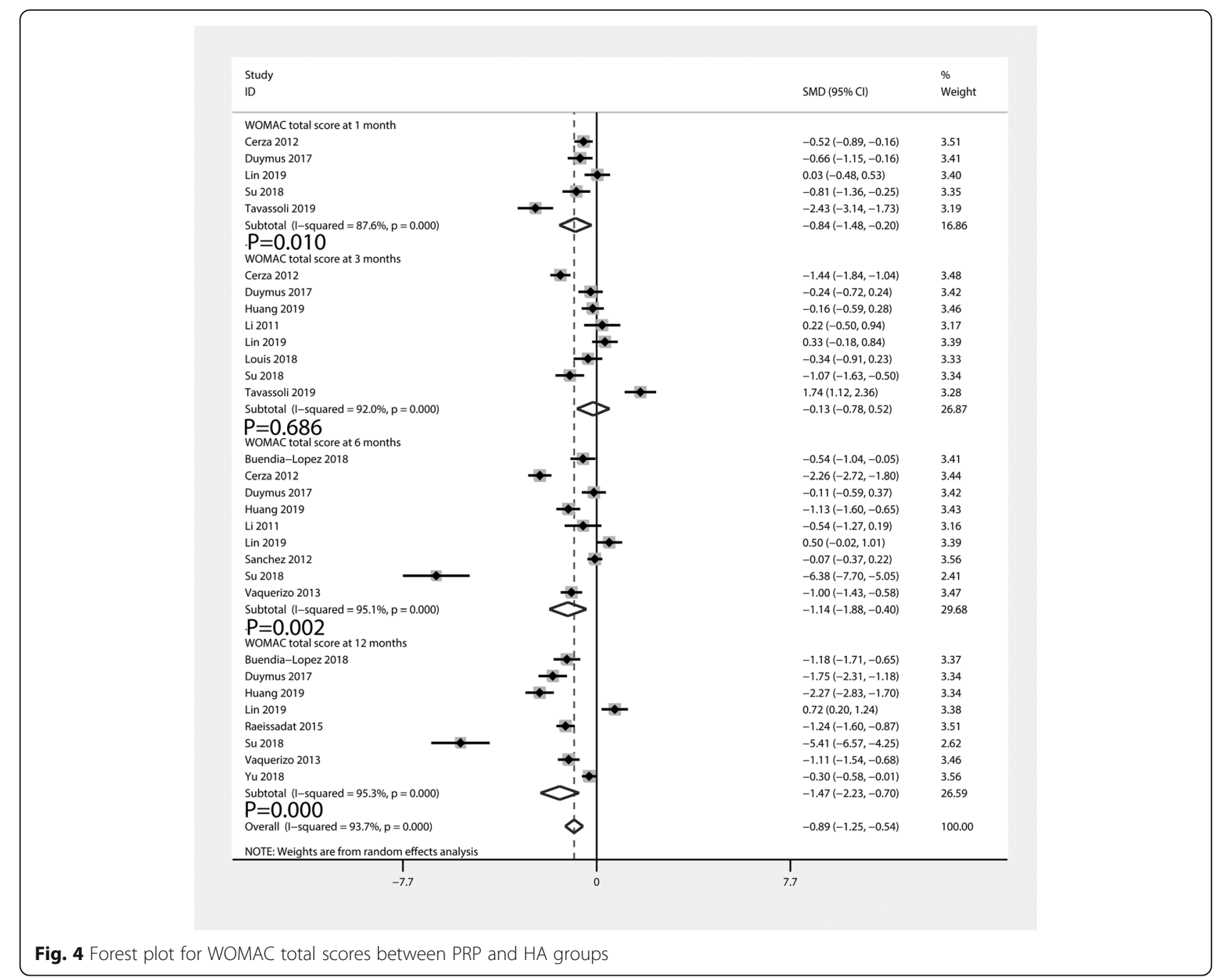

\section{Discussion \\ Main finding}

The pooled results showed that intra-articular PRP injection appeared to be more efficacious than HA injection for the treatment of $\mathrm{KOA}$ in terms of short-term functional recovery. Moreover, PRP injection was superior to HA injection in terms of long-term pain relief and function improvement. In addition, PRP injection did not increase the risk of adverse events when compared with HA injection. The level of evidence, which was undermined by heterogeneity and/or study design limitations, was moderate or low, indicating that the degree of benefit must be studied although the benefit is conclusive. PRP is an autologous concentrate of human platelets isolated through centrifugation of the patient's blood, containing numerous components containing variety of growth factors, cytokines, and many other bioactive proteins [40].
Based on preclinical research, it is known that PRP ameliorates the degeneration of cartilage by stimulation of mesenchymal stem cell migration, proliferation, and differentiation into articular chondrocytes. PRP affects the progression of $\mathrm{KOA}$ via inhibition of inflammatory cytokines and altering the level of enzymatic expression and thus promotes cartilage repair [41]. Moreover, several clinical trials and systematic reviews have demonstrated that PRP have the ability to relive osteoarthritic symptoms up to 12 months postinjection, including pain, stiffness, and function failure [42].

HA is the most important component of articular fluid and responsible for the viscoelastic and lubricant capabilities in joints [43]. It is involved in chondroprotection, proteoglycan, and glycosaminoglycan synthesis as well as antiinflammation. In addition, intra-articular HA injection can significantly reduce the apoptosis rates of chondrocytes [44]. Clinical researches have shown HA injection in patients with 


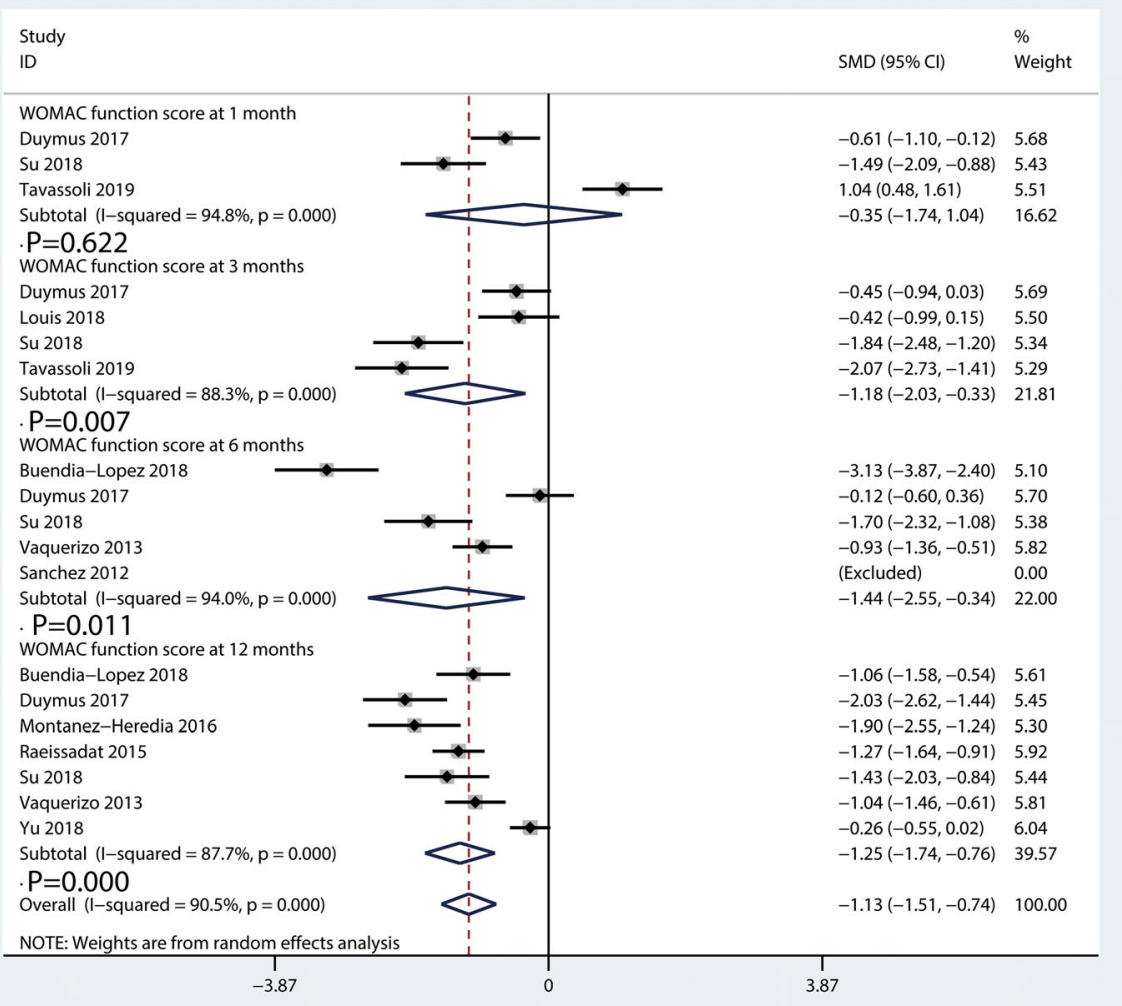

Fig. 5 Forest plot for WOMAC function scores between PRP and HA groups

KOA has the potential to reduce knee pain, improve function, and quality of life [39].

Interestingly, numerous studies have focused on the clinical efficacy between PRP and HA in the KOA treatment. Duymus et al. [26] compared the efficacy of intraarticular injections of PRP with HA for KOA treatment. They found that PRP injection was more successful than HA injection in the treatment of mild-moderate knee OA. PRP application could provide at least 12 months of pain-free daily living activities. Similarly, Lin et al. [17] investigated the discrepancy between PRP and HA in therapy of KOA and suggested that intra-articular injections of leukocyte-poor PRP (LP-PRP) improved function recovery for at least 1 year in patients with mild-tomoderate osteoarthritis of the knee. Furthermore, Ahmad et al. explored the clinical outcomes of PRP injection with changes in the ultrasonography structural appearance [22]. They observed that intra-articular injections of PRP were associated with improved synovial hypertrophy and vascularity scores and less effusion. However, PRP injection failed to perform better efficacy than HA injection in several clinical studies. Filardo et al. [19] found that the patients with PRP injection could not obtain a better clinical outcome than those treated with HA injection. With a long-term follow-up of 5 years, Di Martino et al. [25] concluded that PRP injection did not provide an overall superior clinical improvement compared with HA injection in terms of functional improvement at any follow-up point. Although LP-PRP injection showed more effective in terms of clinical improvement with respect to $\mathrm{HA}$ injection, there was no influence on the X-ray and MRI performance of cartilage progression at 52 weeks follow-up.

Therefore, it still remains a contradiction whether PRP injection is superior to HA injection in the treatment of KOA. Previous systematic review and meta-analysis also evaluated the efficacy of PRP injection compared with HA injection in the treatment of KOA. Laudy et al. [45] enrolled 10 trials and found that PRP injection performed better clinical outcomes than HA injection on pain reduction at 6 months postinjection. Recent meta-analysis by Han et al. [44] pooled 14 RCTs and suggested that PRP injection might be more effective with respect to HA injection in terms of long-term pain relief and functional improvement. The biggest flaw of this meta-analysis was that they included bilateral knee OA, and thus, a large 


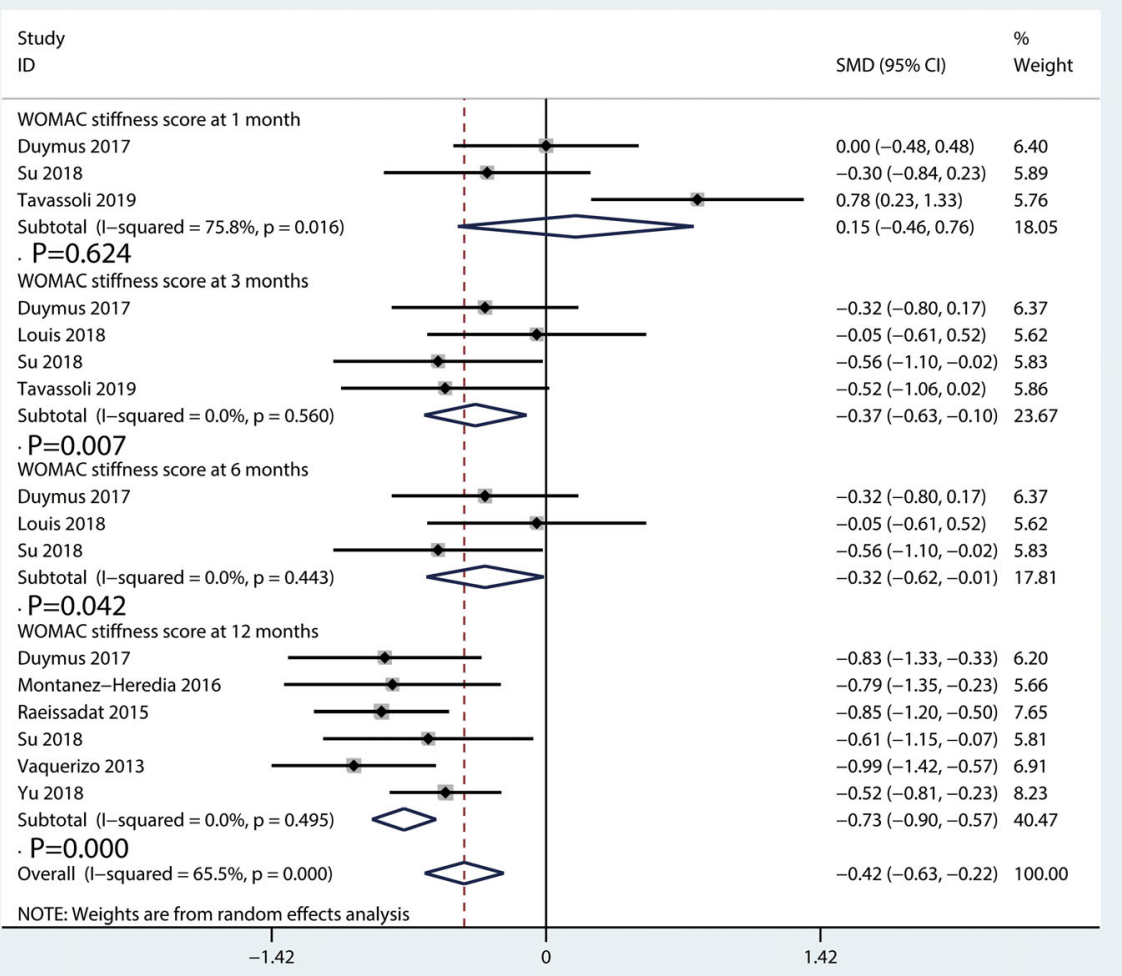

Fig. 6 Forest plot for WOMAC stiffness scores between PRP and HA groups

clinical heterogeneity existed. However, Zhang et al. [13] analyzed 13 studies (10 RCTs and 3 non-randomized studies) and concluded that PRP injection was not obviously superior to HA in KOA. Pooled RCTs and nonRCTs for meta-analysis violates the PRISMA guideline for meta-analysis, and selection bias is ineluctable. The present study is, to our knowledge, the most comprehensive, up-to-date, and with the largest sample size $(n=19$; totally, 1281 patients) meta-analysis undertaken to estimate the efficacy and safety of PRP versus HA in OA.

Limitations of current meta-analyses should be noted. Due to the limited evidence available, previous metaanalysis data extracted from retrospective studies [46] and even case series [47], which might bring significant bias for the overall analysis. Most comparisons included only 1 or 2 studies due to the small number of clinical trials pooled for meta-analysis. More RCTs are responsible for the evaluation of the efficacy of PRP injection on pain relief and function improvement compared to HA injection. Our meta-analysis included 20 RCTs to investigate the efficacy of PRP injection on pain relief and function recovery compared with HA injection in patients with KOA. In shortterm period postinjection (no more than 3 months), PRP injection resulted in better WOMAC function score at 1 month and WOMAC stiffness function score, stiffness score, and IKDC at 3 months compared with HA injection. PRP injection and HA injection had similar effects with respect to the WOMAC pain scores, WOMAC total scores, and VAS scores at 1 month and 3 months. And also, the patients with PRP injection showed similar effects in IKDC and EQ-VAS scores at 2 months, and KOOS at 3 months. In long-term period postinjection (no less than 6 months), we found that better clinical results were achieved in the PRP injection group compared with the HA injection group in terms of WOMAC pain, function, stiffness, and total scores and VAS scores at 6 months and 12 months. Moreover, the patients with PRP treatment showed better performance with respect to IKDC at 6 months and EQ-VAS at 12 months. Nevertheless, there was no significant difference between groups in terms of bias for the overall analysis. Most comparisons included only 1 or 2 studies due to the small number of clinical trials pooled for meta-analysis. More RCTs are responsible for the evaluation of the efficacy of PRP injection on pain relief and function improvement compared with HA injection.

Another issue that affects the effects of PRP is the leukocyte concentration in PRP composition, which may contain more proinflammatory cytokines and be 


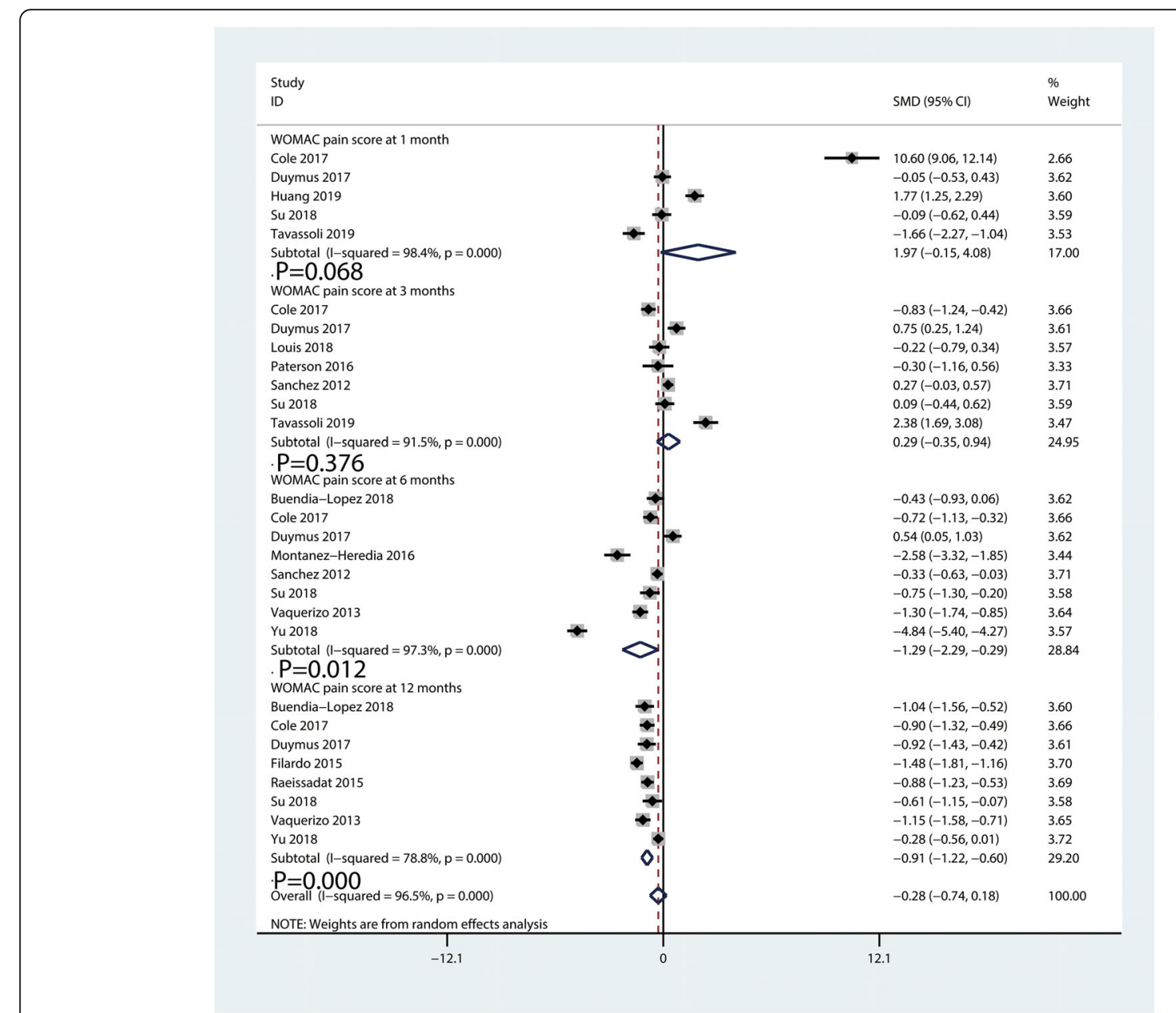

Fig. 7 Forest plot for WOMAC pain scores between PRP and HA groups

detrimental to cartilage repair. Subgroup analyses were used to identify the potential heterogeneity of the results. A study conducted by Riboh et al. [48] compared LP-PRP and LR-PRP in the treatment of KOA and found that LPPRP injections resulted in significantly improved WOMAC scores compared with HA or placebo. These results were consistent with our subgroup findings.

Vilchez-Cavazos et al. [45] conducted a meta-analysis and revealed that single injection was as effective as multiple PRP injections in pain improvement; however, multiple injections seemed more effective in joint functionality than a single injection at 6 months. Similarly, most of these results were also consistent in different PRP spinning approaches, whether with an activator use and PRP species (fresh or frozen), which suggested that these factors might have little influence on the efficacy of PRP.

\section{Limitations}

Some limitations in the current study should be interpreted. Firstly, the main limitation is that most overall analyses are accompanied with high heterogeneity. The high heterogeneity among pooled results has weakened the persuasion of the conclusion. Although we tried to compensate for methodological deficiencies by performing stratified analyses, some results remained inconclusive since several reports lacked the documentation of the key factors. Secondly, although 19 RCTs were included in this study, some indexes such as WOMAC function and stiffness score at 1 month, IKDC at 3 months, EQ-VAS at 2 months, and KOOS at 3 months were analyzed by the data extracted from only two studies. Moreover, similar to the previous meta-analysis studies, we evaluated the efficacy between PRP and HA within 1 year on the account of limited follow-up. Some RCTs explored the long-term follow-up ( 52 weeks by Buendia-Lopez et al. [23] and 5 years by Di Martino et al. [14]). However, we were unable to pool the longterm results from the limited data. Thirdly, almost all included RCTs used subjective questionnaires to deduce the treatment effects. Objective findings such as 


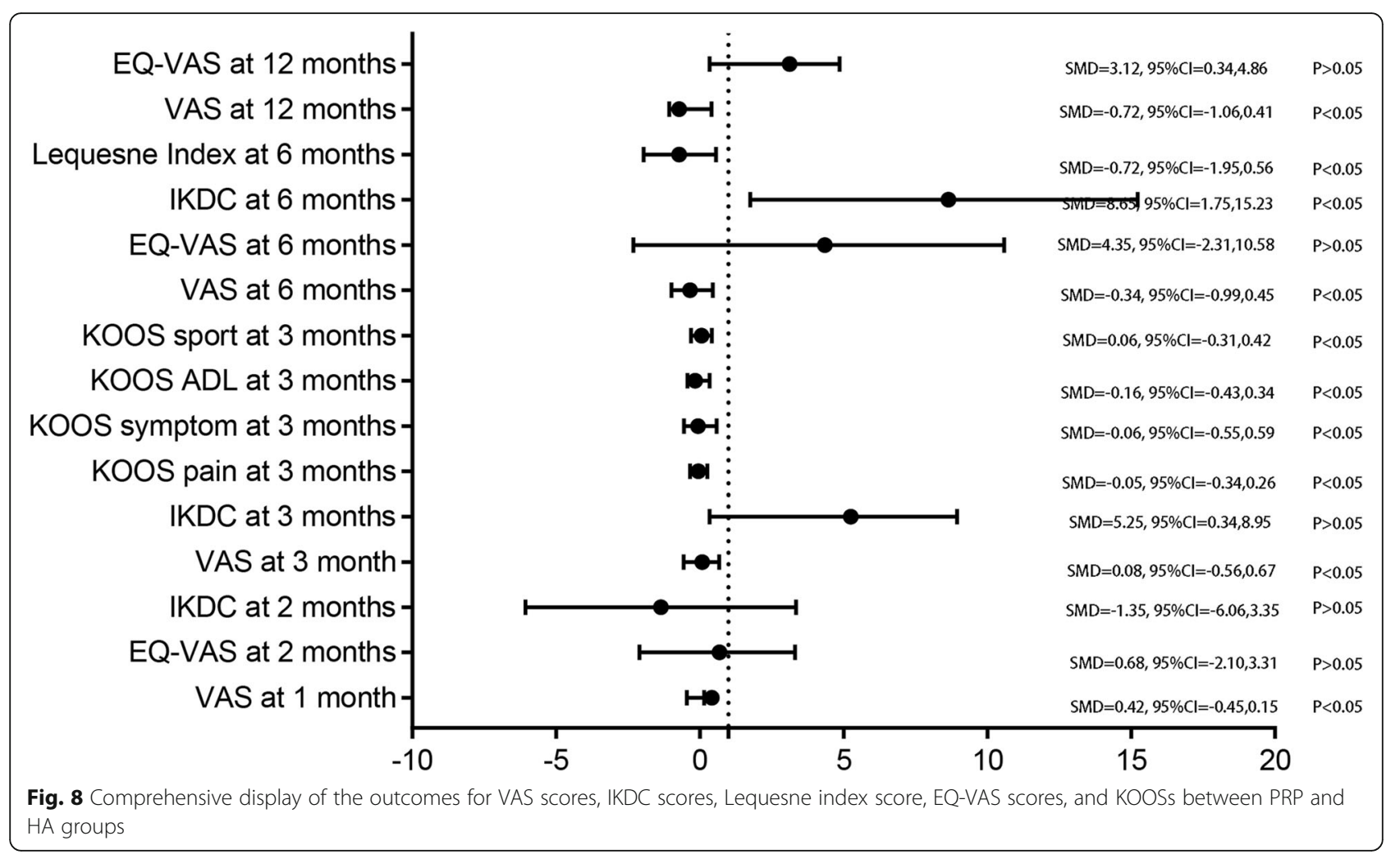

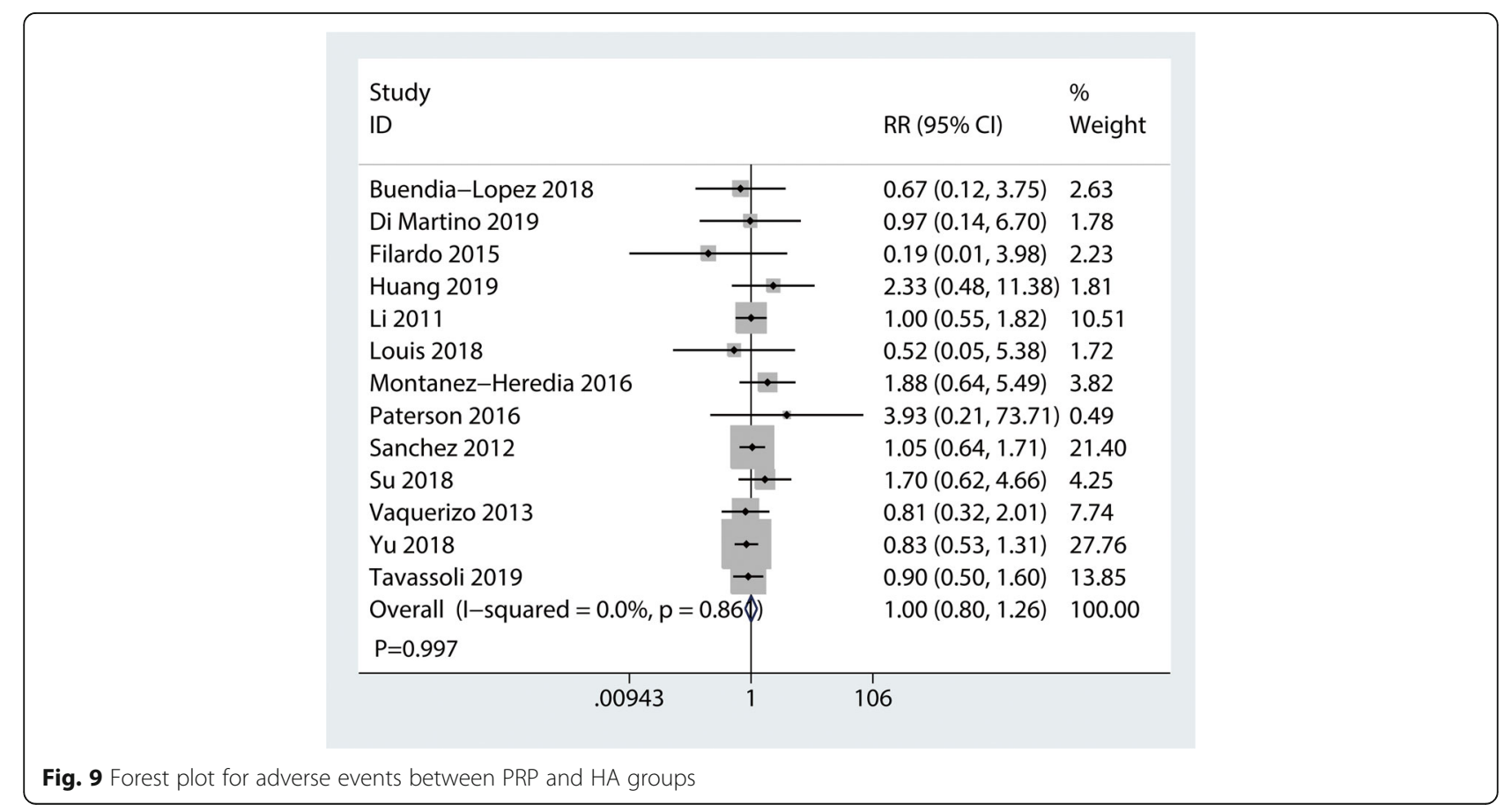


Table 3 Subgroup analyses of PRP compared with HA for WOMAC total scores at 12 months

\begin{tabular}{|c|c|c|c|c|c|}
\hline Subgroup & No. of trials & $\begin{array}{l}\text { Standard mean difference } \\
(95 \% \mathrm{Cl})\end{array}$ & $P$ value & $\begin{array}{l}P^{2} \\
(\%)\end{array}$ & $\begin{array}{l}\text { Test of } \\
\text { interaction, } P\end{array}$ \\
\hline Total & 8 & $-1.47(-2.23,-0.70)$ & 0.000 & 95.3 & \\
\hline \multicolumn{6}{|l|}{ Number of PRP injections } \\
\hline 1 & 4 & $-1.15(-2.14,-0.85)$ & 0.000 & 69.3 & \multirow[t]{2}{*}{0.006} \\
\hline$\geq 2$ & 4 & $-1.68(-2.35,-0.72)$ & 0.000 & 98.2 & \\
\hline \multicolumn{6}{|l|}{ PRP spinning approach } \\
\hline Single & 3 & $-1.13(-2.22,-0.85)$ & 0.000 & 0.0 & \multirow[t]{2}{*}{0.028} \\
\hline Double & 5 & $-1.62(-2.34,-1.11)$ & 0.000 & 88.4 & \\
\hline \multicolumn{6}{|l|}{ PRP classification } \\
\hline LPP & 3 & $-2.89(-6.55,-0.68)$ & 0.000 & 82.4 & \multirow[t]{2}{*}{0.002} \\
\hline LRP & 5 & $0.86(0.15,1.56)$ & 0.000 & 83.5 & \\
\hline \multicolumn{6}{|l|}{ Fresh or frozen PRP } \\
\hline Fresh & 5 & $0.78(0.54,1.01)$ & 0.000 & 57.8 & \multirow[t]{2}{*}{0.105} \\
\hline Frozen & 3 & $0.50(0.33,0.67)$ & 0.000 & 88.1 & \\
\hline \multicolumn{6}{|l|}{ Activator used } \\
\hline Yes & 4 & $-2.78(-4.32,-1.15)$ & & 82.1 & \multirow[t]{2}{*}{0.031} \\
\hline No & 4 & $0.58(0.12,1.58)$ & & 93.4 & \\
\hline \multicolumn{6}{|l|}{ Risk of bias } \\
\hline Low & 6 & $-1.23(-2.08,-0.35)$ & 0.002 & 85.9 & \multirow[t]{2}{*}{0.254} \\
\hline Unclear/high & 2 & $-1.33(-2.24,-0.46)$ & 0.004 & 89.4 & \\
\hline \multicolumn{6}{|l|}{ Molecular weight } \\
\hline High & 4 & $-1.90(-4.53,0.73)$ & 0.157 & 97.9 & \multirow[t]{2}{*}{0.003} \\
\hline Low & 4 & $-1.31(-1.97,-0.64)$ & 0.000 & 92.2 & \\
\hline \multicolumn{6}{|l|}{ Structure } \\
\hline Cross-linked & 4 & $-2.06(-3.20,-0.92)$ & 0.352 & 96.2 & \multirow[t]{2}{*}{0.000} \\
\hline Not cross-linked or unclear & 4 & $-0.57(-1.78,0.63)$ & 0.000 & 95.0 & \\
\hline
\end{tabular}

magnetic resonance and ultrasound seem to be needed in the efficacy evaluation. Finally, the administration of PRP injection was varied in the included RCTs. The present study failed to recommend the optimal administration dosage and interval because of the insufficient data. Therefore, more well-designed RCTs with longterm follow-up are still necessary.

\section{Conclusion}

Intra-articular PRP injection appeared to be more efficacious than $\mathrm{HA}$ injection for the treatment of $\mathrm{KOA}$ in terms of short-term functional recovery. Moreover, PRP injection was superior to HA injection in terms of longterm pain relief and function improvement. In addition, PRP injection did not increase the risk of adverse events when compared with HA injection. Additional RCTs are needed to identify the optimal doses and intervals of PRP and HA.

\section{Supplementary information}

Supplementary information accompanies this paper at https://doi.org/10. 1186/s13018-020-01919-9.

Additional file 1. Search strategies in PubMed database.

Additional file 2. PRISMA 2009 Flow Diagram.

\section{Abbreviations}

PRP: Platelet-rich plasma; HA: Hyaluronic acid; KOA: Knee osteoarthritis; WOMAC: Western Ontario and McMaster Universities Arthritis Index; IKDC: International Knee Documentation Committee; KOOS: Knee Injury and Osteoarthritis Outcome Score; ACR: American College of Rheumatology; PRIS MA: Preferred Reporting Items for Systematic Reviews and Meta-analysis; MeSH: Medical Subject Headings; SMD: Standard mean difference;

$\mathrm{Cl}$ : Confidence interval; RRs: Risk ratios

\section{Acknowledgements}

Not applicable

\section{Authors' contributions}

JZT and MJN conceived the study design. JZZ performed the study, collected the data, and contributed to the study design. GCZ and QZ 
prepared the manuscript. BW edited the manuscript. The authors read and approved the final manuscript.

\section{Funding}

There is no funding for this article.

\section{Availability of data and materials}

We state that the data will not be shared since all the raw data are present in the figures included in the article.

\section{Ethics approval and consent to participate}

Not applicable

\section{Consent for publication}

Not applicable

\section{Competing interests}

The authors declare that they have no competing interests.

Received: 11 June 2020 Accepted: 24 August 2020

Published online: 11 September 2020

\section{References}

1. Phillips M, Vannabouathong C, Devji T, et al. Differentiating factors of intraarticular injectables have a meaningful impact on knee osteoarthritis outcomes: a network meta-analysis. Knee Surg Sports Traumatol Arthrosc. 2020. https://doi.org/10.1007/s00167-019-05763-1.

2. Lespasio MJ, Piuzzi NS, Husni ME, et al. Knee osteoarthritis: a primer. Perm J. 2017;21:16-183. https://doi.org/10.7812/tpp/16-183.

3. Zhao Z, Ma JX, Ma XL. Different intra-articular injections as therapy for hip osteoarthritis: a systematic review and network meta-analysis. Arthroscopy. 2020. https://doi.org/10.1016/j.arthro.2019.09.043

4. Hussain SM, Neilly DW, Baliga S, et al. Knee osteoarthritis: a review of management options. Scott Med J. 2016;61:7-16. https://doi.org/10.1177/ 0036933015619588 .

5. Fonsi M, El Amrani Al, Gervais F, et al. Intra-articular hyaluronic acid and chondroitin sulfate: pharmacokinetic investigation in osteoarthritic rat models. Curr Ther Res Clin Exp. 2020;92:100573. https://doi.org/10.1016/j. curtheres.2019.100573.

6. Ferreira RM, Duarte JA, Goncalves RS. Non-pharmacological and nonsurgical interventions to manage patients with knee osteoarthritis: an umbrella review. Acta Reumatol Port. 2018:43:182-200.

7. Smith KC, Losina E. Budget impact of funding an intensive diet and exercise program for overweight and obese patients with knee osteoarthritis. ACR Open Rheumatol. 2020;2:26-36. https://doi.org/10.1002/acr2.11090.

8. Persson MSM, Stocks J, Walsh DA, et al. The relative efficacy of topical nonsteroidal anti-inflammatory drugs and capsaicin in osteoarthritis: a network meta-analysis of randomised controlled trials. Osteoarthr Cartil. 2018;26: 1575-82. https://doi.org/10.1016/j.joca.2018.08.008.

9. Zhang Q, Young L, Li F. Network meta-analysis of various nonpharmacological interventions on pain relief in older adults with osteoarthritis. Am J Phys Med Rehabil. 2019;98:469-78. https://doi.org/10. 1097/phm.0000000000001130.

10. Cook CS, Smith PA. Clinical Update: Why PRP Should be your first choice for injection therapy in treating osteoarthritis of the knee. Curr Rev Musculoskelet Med. 2018;11:583-92. https://doi.org/10.1007/s12178-0189524-X.

11. Wu Q, Luo X, Xiong Y, et al. Platelet-rich plasma versus hyaluronic acid in knee osteoarthritis: a meta-analysis with the consistent ratio of injection. J Orthop Surg (Hong Kong). 2020;28:2309499019887660. https://doi.org/10. $1177 / 2309499019887660$

12. Chen $P$, Huang $L, M a ~ Y$, et al. Intra-articular platelet-rich plasma injection for knee osteoarthritis: a summary of meta-analyses. J Orthop Surg Res. 2019:14: 385. https://doi.org/10.1186/s13018-019-1363-y.

13. Zhang HF, Wang CG, Li H, et al. Intra-articular platelet-rich plasma versus hyaluronic acid in the treatment of knee osteoarthritis: a meta-analysis. Drug Des Devel Ther. 2018;12:445-53. https://doi.org/10.2147/dddt.s156724.

14. Kolasinski SL, Neogi T, Hochberg MC, et al. 2019 American College of Rheumatology/Arthritis Foundation Guideline for the Management of Osteoarthritis of the Hand, Hip, and Knee. Arthritis Rheum. 2020, [Epub ahead of print]. https://doi.org/10.1002/art.41142.
15. Veronesi F, Pagani S, Torricelli P, et al. PRP and MSCs on tenocytes artificial wound healing: an in vitro study comparing fresh and frozen PRP. Histo Histopathol. 2018;33:1323-34. https://doi.org/10.14670/hh-18-018.

16. Kim SJ, Yeo SM, Noh SJ, et al. Effect of platelet-rich plasma on the degenerative rotator cuff tendinopathy according to the compositions. J Orthop Surg Res. 2019:14:408. https://doi.org/10.1186/s13018-019-1406-4.

17. Lin KY, Yang CC, Hsu CJ, et al. Intra-articular injection of platelet-rich plasma is superior to hyaluronic acid or saline solution in the treatment of mild to moderate knee osteoarthritis: a randomized, double-blind, triple-parallel, placebo-controlled clinical trial. Arthroscopy. 2019;35:106-17. https://doi.org/ 10.1016/j.arthro.2018.06.035.

18. Di Y, Han C, Zhao L, et al. Is local platelet-rich plasma injection clinically superior to hyaluronic acid for treatment of knee osteoarthritis? A systematic review of randomized controlled trials. Arthritis Res Ther. 2018;20: 128. https://doi.org/10.1186/s13075-018-1621-0.

19. Filardo G, Di Matteo B, Di Martino A, et al. Platelet-rich plasma intra-articular knee injections show no superiority versus viscosupplementation: a randomized controlled trial. Am J Sports Med. 2015;43:1575-82. https://doi. org/10.1177/0363546515582027.

20. Cole BJ, Karas V, Hussey K, et al. Hyaluronic acid versus platelet-rich plasma: a prospective, double-blind randomized controlled trial comparing clinical outcomes and effects on intra-articular biology for the treatment of knee osteoarthritis. Am J Sports Med. 2017:45:339-46. https://doi.org/10.1177/ 0363546516665809

21. Liberati A, Altman DG, Tetzlaff J, et al. The PRISMA statement for reporting systematic reviews and meta-analyses of studies that evaluate healthcare interventions: explanation and elaboration. Bmj. 2009;339:b2700. https://doi. org/10.1136/bmj.b2700.

22. Ahmad HS, Farrag SE, Okasha AE, et al. Clinical outcomes are associated with changes in ultrasonographic structural appearance after platelet-rich plasma treatment for knee osteoarthritis. Int J Rheum Dis. 2018;21:960-6. https://doi.org/10.1111/1756-185x.13315.

23. Buendia-Lopez D, Medina-Quiros M, Fernandez-Villacanas Marin MA. Clinical and radiographic comparison of a single LP-PRP injection, a single hyaluronic acid injection and daily NSAID administration with a 52-week follow-up: a randomized controlled trial. J Orthop Traumatol. 2018;19:3. https://doi.org/10.1186/s10195-018-0501-3.

24. Cerza F, Carni S, Carcangiu A, et al. Comparison between hyaluronic acid and platelet-rich plasma, intra-articular infiltration in the treatment of gonarthrosis. Am J Sports Med. 2012;40:2822-7. https://doi.org/10.1177/ 0363546512461902

25. Di Martino A, Di Matteo B, Papio T, et al. Platelet-rich plasma versus hyaluronic acid injections for the treatment of knee osteoarthritis: results at 5 years of a double-blind, randomized controlled trial. Am J Sports Med. 2019:47:347-54. https://doi.org/10.1177/0363546518814532

26. Duymus TM, Mutlu S, Dernek B, et al. Choice of intra-articular injection in treatment of knee osteoarthritis: platelet-rich plasma, hyaluronic acid or ozone options. Knee Surg Sports Traumatol Arthrosc. 2017;25:485-92. https://doi.org/10.1007/s00167-016-4110-5.

27. Gormeli G, Gormeli CA, Ataoglu B, et al. Multiple PRP injections are more effective than single injections and hyaluronic acid in knees with early osteoarthritis: a randomized, double-blind, placebo-controlled trial. Knee Surg Sports Traumatol Arthrosc. 2017;25:958-65. https://doi.org/10.1007/ s00167-015-3705-6.

28. Huang $Y$, Liu $X, X u X$, et al. Intra-articular injections of platelet-rich plasma, hyaluronic acid or corticosteroids for knee osteoarthritis : a prospective randomized controlled study. Orthopade. 2019;48:239-47. https://doi.org/10 1007/s00132-018-03659-5.

29. Li M, Zhang C, Ai Z, et al. Therapeutic effectiveness of intra-knee-articular injection of platelet-rich plasma on knee articular cartilage degeneration. Zhongguo Xiu Fu Chong Jian Wai Ke Za Zhi. 2011;25:1192-6.

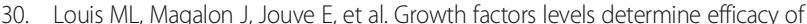
platelets rich plasma injection in knee osteoarthritis: a randomized double blind noninferiority trial compared with viscosupplementation. Arthroscopy. 2018;34:1530-1540.e1532. https://doi.org/10.1016/j.arthro.2017.11.035.

31. Montanez-Heredia E, Irizar S, Huertas PJ, et al. Intra-articular injections of plateletrich plasma versus hyaluronic acid in the treatment of osteoarthritic knee pain: a randomized clinical trial in the context of the Spanish National Health Care System. Int J Mol Sci. 2016;17. https://doi.org/10.3390/ijms17071064.

32. Paterson $\mathrm{KL}$, Nicholls $\mathrm{M}$, Bennell $\mathrm{KL}$, et al. Intra-articular injection of photoactivated platelet-rich plasma in patients with knee osteoarthritis: a double- 
blind, randomized controlled pilot study. BMC Musculoskelet Disord. 2016; 17:67. https://doi.org/10.1186/s12891-016-0920-3.

33. Raeissadat SA, Rayegani SM, Hassanabadi $\mathrm{H}$, et al. Knee osteoarthritis injection choices: platelet-rich plasma (PRP) versus hyaluronic acid (a oneyear randomized clinical trial). Clin Med Insights Arthritis Musculoskelet Disord. 2015:8:1-8. https://doi.org/10.4137/cmamd.s17894.

34. Sanchez M, Fiz N, Azofra J, et al. A randomized clinical trial evaluating plasma rich in growth factors (PRGF-Endoret) versus hyaluronic acid in the short-term treatment of symptomatic knee osteoarthritis. Arthroscopy. 2012; 28:1070-8. https://doi.org/10.1016/j.arthro.2012.05.011.

35. Su K, Bai Y, Wang J, et al. Comparison of hyaluronic acid and PRP intraarticular injection with combined intra-articular and intraosseous PRP injections to treat patients with knee osteoarthritis. Clin Rheumatol. 2018;37: 1341-50. https://doi.org/10.1007/s10067-018-3985-6.

36. Vaquerizo V, Plasencia MA, Arribas I, et al. Comparison of intra-articular injections of plasma rich in growth factors (PRGF-Endoret) versus Durolane hyaluronic acid in the treatment of patients with symptomatic osteoarthritis: a randomized controlled trial. Arthroscopy. 2013;29:1635-43. https://doi.org/10.1016/j.arthro.2013.07.264.

37. Yu W, Xu P, Huang G, et al. Clinical therapy of hyaluronic acid combined with platelet-rich plasma for the treatment of knee osteoarthritis. Exp Ther Med. 2018;16:2119-25. https://doi.org/10.3892/etm.2018.6412.

38. Tavassoli M, Janmohammadi N, Hosseini A, et al. Single- and double-dose of platelet-rich plasma versus hyaluronic acid for treatment of knee osteoarthritis: a randomized controlled trial. World J Orthop. 2019;10:310-26. https://doi.org/10.5312/wjo.v10.19.310.

39. Li Q, Qi X, Zhang Z. Intra-articular oxygen-ozone versus hyaluronic acid in knee osteoarthritis: a meta-analysis of randomized controlled trials. Int J Surg. 2018;58:3-10. https://doi.org/10.1016/j.jiju.2018.08.007.

40. Dai $W L$, Zhou AG, Zhang H, et al. Efficacy of platelet-rich plasma in the treatment of knee osteoarthritis: a meta-analysis of randomized controlled trials. Arthroscopy. 2017;33:659-670.e651. https://doi.org/10.1016/j.arthro. 2016.09.024.

41. Shen $L$, Yuan $T$, Chen $S$, et al. The temporal effect of platelet-rich plasma on pain and physical function in the treatment of knee osteoarthritis: systematic review and meta-analysis of randomized controlled trials. J Orthop Surg Res. 2017;12:16. https://doi.org/10.1186/s13018-017-0521-3.

42. Johal H, Khan M, Yung SP, et al. Impact of platelet-rich plasma use on pain in orthopaedic surgery: a systematic review and meta-analysis. Sports Health. 2019;11:355-66. https://doi.org/10.1177/1941738119834972.

43. Parisi S, Ditto MC, Priora M, et al. Ultrasound-guided intra-articular injection: efficacy of hyaluronic acid compared to glucocorticoid in the treatment of knee osteoarthritis. Minerva Med. 2019;110:515-23. https://doi.org/10.23736/ s0026-4806.19.06190-1.

44. Han Y, Huang H, Pan J, et al. Meta-analysis comparing platelet-rich plasma vs hyaluronic acid injection in patients with knee osteoarthritis. Pain Med. 2019;20:1418-29. https://doi.org/10.1093/pm/pnz011.

45. Vilchez-Cavazos F, Millan-Alanis JM, Blazquez-Saldana J, et al. Comparison of the clinical effectiveness of single versus multiple injections of platelet-rich plasma in the treatment of knee osteoarthritis: a systematic review and meta-analysis. Orthop J Sports Med. 2019;7:2325967119887116. https://doi. org/10.1177/2325967119887116.

46. Laudy AB, Bakker EW, Rekers M, et al. Efficacy of platelet-rich plasma injections in osteoarthritis of the knee: a systematic review and metaanalysis. Br J Sports Med. 2015;49:657-72. https://doi.org/10.1136/bjsports2014-094036.

47. Chang KV, Hung CY, Aliwarga F, et al. Comparative effectiveness of plateletrich plasma injections for treating knee joint cartilage degenerative pathology: a systematic review and meta-analysis. Arch Phys Med Rehabil. 2014;95:562-75. https://doi.org/10.1016/j.apmr.2013.11.006.

48. Riboh JC, Saltzman BM, Yanke AB, et al. Effect of leukocyte concentration on the efficacy of platelet-rich plasma in the treatment of knee osteoarthritis. Am J Sports Med. 2016;44:792-800. https://doi.org/10.1177/ 0363546515580787.

\section{Publisher's Note}

Springer Nature remains neutral with regard to jurisdictional claims in published maps and institutional affiliations.

Ready to submit your research? Choose BMC and benefit from:

- fast, convenient online submission

- thorough peer review by experienced researchers in your field

- rapid publication on acceptance

- support for research data, including large and complex data types

- gold Open Access which fosters wider collaboration and increased citations

- maximum visibility for your research: over $100 \mathrm{M}$ website views per year

At BMC, research is always in progress.

Learn more biomedcentral.com/submissions 